\title{
Perdas de grãos e distribuição de palha na colheita mecanizada de soja
}

\author{
Carlos Alessandro Chioderoli ("); Rouverson Pereira da Silva; Rafael Henrique de Freitas Noronha; \\ Marcelo Tufaile Cassia; Edvaldo Pereira dos Santos
}

Faculdade de Ciências Agrárias e Veterinárias de Jaboticabal (FCAV/UNESP), Departamento de Engenharia Rural, Área de Máquinas e Mecanização Agrícola, Via de Acesso Prof. Paulo Donato Castellane, 14884-900 Jaboticabal (SP), Brasil.

(*) Autor correspondente: ca.chioderoli@uol.com.br

Recebido: 11/abr./2011; Aceito: 16/dez./2011

\section{Resumo}

Considerando que a colheita é a etapa final de um processo produtivo e que as perdas devem ser mantidas dentro de padrões aceitáveis, as regulagens das colhedoras e as características agronômicas da cultura deverão permitir menores perdas quantitativas para que possa atingir o máximo nível de qualidade e maior sustentabilidade do sistema produtivo. Este trabalho teve como objetivo determinar as perdas quantitativas, distribuição de palha e características operacionais da colhedora por meio do controle estatístico de processo, bem como verificar a qualidade da operação de colheita. O trabalho foi realizado no município de Santa Juliana (MG), com as coordenadas geográficas de referência 19 18'Se 4731'O. A área amostrada constou de 40 pontos distribuídos em malha retangular, equidistantes de 50 m, definidos sequencialmente a partir do momento de início da colheita. Em cada ponto foi determinado o teor de água dos grãos, número de vagens por planta, altura de inserção de primeira vagem, altura de plantas, produtividade, distribuição de palha e características operacionais da colhedora. A perda de grãos ocasionada pela colhedora esteve fora dos limites de controle, porém dentro dos padrões aceitáveis de perdas para cultura da soja. A qualidade da operação de colheita e as regulagens da colhedora foram dependentes da velocidade de deslocamento. A distribuição de palha esteve próxima do desejável para o sistema de semeadura direta. A utilização das cartas de controle foi eficiente na identificação dos pontos fora de controle e na avaliação da qualidade do processo de colheita.

Palavras-chave: cartas de controle, colhedora, velocidade de colheita.

\section{Losses of grains and distribution of straw in soybean mechanized harvesting}

\section{Abstract}

Considering that the harvest is the final step of a productive process and the losses should be kept within acceptable standards, the settings of harvesters should reduce quantitative losses and warrant high quality and sustainability of the productive system. This study aimed to determine the quantitative losses, straw distribution and operational characteristics of the harvester through the statistical process control, and to verify the quality of the harvesting operation. The study was conducted in Santa Juliana, State of Minas Gerais, Brazil (19¹8' S and 47031' W). The area sampled consisted in 40 points distributed in rectangular grid, equidistant from 50 m, defined sequentially after harvest starting. At each point, we evaluated the water content of the grains, number of pods per plant; insertion height of first pod; plant of height; productivity; straw distribution and operational characteristics of the harvester. The grain loss caused by the harvester was outside the control limits, but within the acceptable standards of losses for soybean crop. The quality of the harvesting operation and adjustments of the harvester were dependent on the speed displacement. The straw distribution proved to be near of the desirable for no-tillage system. The use of control charts was efficient for identifying the points out of control and assessing the quality of harvesting process

Key words: control charts, combine, speed of harvest. 


\section{INTRODUÇÃO}

A soja (Glycine max. (L.) Merril) é uma cultura de grande importância na economia brasileira, com área de $24 \mathrm{mi}-$ lhôes de hectares para semeaduras realizadas até dezembro de 2010 , representando aumento de $2,4 \%$ em relação à safra 2009/2010 e com produtividade de 70,3 milhóes de toneladas, com aumento de $2,3 \%$ em relação à safra anterior (CONAB, 2011).

As perdas na colheita são influenciadas tanto por fatores inerentes à cultura em especial, como por fatores relacionados à colhedora (Ferreira et al., 2007; CARVAlHo FilHo et al., 2005). O processo produtivo da soja pode ser totalmente mecanizado e um dos pontos importantes dessa mecanização é a regulagem a ser utilizada na colhedora. A regulagem deve ser adequada conforme a cultura, material genético, teor de água do grão, velocidade da colhedora e finalidade dos grãos.

Ferreira et al. (2007) constataram diferenças quanto às perdas quantitativas em função das velocidades de deslocamento de uma colhedora de fluxo tangencial com potência de $103 \mathrm{~kW}(140 \mathrm{cv})$, e para as menores velocidades ocorreram as maiores perdas. A interação entre os fatores velocidade e abertura de côncavo ( 39 e 29 mm) ocasionou diferença nas perdas somente para a menor abertura, também maiores para a menor velocidade. MEsQuita et al. (2006) afirmam que as menores perdas na colheita sáo observadas para velocidades próximas à faixa de 4,5 a 5,5 $\mathrm{km} \mathrm{h}^{-1}$.

Pesquisa realizada por Toledo et al. (2008), trabalhando com caracterização das perdas e a distribuição de cobertura vegetal em colheita mecanizada de soja, observaram que tais perdas e distribuição da cobertura vegetal tiveram, respectivamente, coeficientes de variaçáo altos e médios, e a distribuição de palha manteve-se em processo controlado, porém com tendência à maior variabilidade, que pode ter sido influenciada pelo relevo mais inclinado.

A fragmentaçáo e a distribuição da palha são realizadas, na maioria das vezes, por meio da colhedora, que possui em seus mecanismos um dispositivo picador do tipo aletas para essa finalidade. A distribuição uniforme da palha é de fundamental importância para o bom desempenho da semeadora, permitindo maior eficiência operacional, melhor controle de plantas daninhas e distribuição regular de sementes, promovendo maior lucratividade e qualidade operacional.

O Controle Estatístico de Processo (CEP) tem como objetivo detectar rapidamente alteraçóes dos parâmetros de determinados processos para que os problemas possam ser corrigidos antes que muitos itens não conformes sejam produzidos (Mingoti e Fidelis, 2001). O controle de qualidade é perfeitamente adaptável ao sistema de produção agrícola. Com a correção e a eliminação de desperdícios e falhas, redução de custos e aumento da produtividade, inúmeras vantagens serão acrescidas à competitividade do campo (Bonilla, 1994).
Considerando-se que a qualidade da operação de colheita está relacionada com a regulagem das máquinas e fatores inerentes à cultura, o trabalho teve como objetivo determinar perdas quantitativas, distribuiçáo de palha e determinaçẫo das características operacionais da colhedora por meio do controle estatístico do processo, bem como verificar a qualidade da operação.

\section{MATERIAL E MÉTODOS}

O presente trabalho foi realizado no município de Santa Juliana (MG), situado a oeste do Alto Paranaíba, na safra 2009/2010, com as coordenadas geográficas de referência $19^{\circ} 18^{\prime} \mathrm{S}$ e $47^{\circ} 31^{\prime} \mathrm{O}$, e altitude local de 980 metros. O solo da área foi classificado como Latossolo VermelhoAmarelo (EMbrapa, 2006).

A área amostrada constou de 40 pontos distribuídos em malha retangular, espaçados de 4 x 10 pontos, equidistantes de $50 \mathrm{~m}$, selecionados sequencialmente a partir do início da colheita. A cultivar de soja analisada foi a Nidera NA 8500 , semeada por sistema de semeadura direta no dia 25/11/2009, em área em pousio. A área foi cultivada anteriormente com soja por um período de cinco anos no Sistema Plantio Direto. A densidade de semeadura foi de 15 sementes $\mathrm{m}^{-1}$, com espaçamento entrelinhas de 0,45 $\mathrm{m}$, com populaçáo aproximada de 334 mil plantas ha-1.

A colheita foi realizada em 14/4/2010 com colhedora combinada de fluxo axial de duplo rotor, motor de 290 kW de potência $(394 \mathrm{cv})$, eletrônico, sistema de injeção "Common-Rail", intercooler ar-ar, equipada com plataforma de corte de 9,14 $\mathrm{m}$ de largura, picador de palha, distribuidor de palhiço e monitor de desempenho Intelliview, utilizado para coleta das especificaçóes e das variáveis de desempenho da máquina (potência no motor, rotação no motor, velocidade do rotor, velocidade de deslocamento e consumo de combustível).

O teor de água dos grãos foi determinado em cada ponto por meio de medidor portátil. Para determinar as características agronômicas da cultura, foram coletadas plantas, em três linhas, na distância de dois metros em cada linha, correspondendo à área útil da parcela. A altura de planta, inserção de primeira vagem e número de vagens por planta foram obtidos por meio de mediçáo, com régua milimetrada, de 10 plantas aleatórias da área útil de cada parcela. Para determinação da produtividade de grãos $\left(\mathrm{kg} \mathrm{ha}^{-1}\right)$, foram coletadas as plantas da área útil de cada parcela e posteriormente realizou-se a trilha das plantas coletadas em uma trilhadora estacionária, avaliando-se a massa de grãos e os valores extrapolados para $\mathrm{kg} \mathrm{ha}^{-1}$ (13\% b.u.).

$\mathrm{Na}$ determinação das perdas foram utilizadas armaçôes retangulares, construídas com duas barras metálicas e dois cordôes de náilon, com medidas ajustáveis para obter a mesma largura da plataforma de corte da colhedora em 
estudo, mantendo-se a área interna de $2,0 \mathrm{~m}^{2}$, segundo método proposto por Mesquita et al. (1998). Todos os grãos presentes dentro da armação, após a passagem da colhedora, foram coletados, sendo classificados como: perda provocada pelo sistema de trilha (PGS), para os grãos dentro de vagens dispostas no solo; perda pelo sistema de limpeza (PGL), determinada pela massa de gráos livres encontrados no solo dentro da armaçáo e perda de gráos total (PGT). A PGT foi calculada pela soma aritmética das perdas anteriores, em $\mathrm{kg} \mathrm{ha}^{-1}$. Não foram observadas perdas naturais anteriores à colheita, assim como perdas por deficiência na altura de corte. A perda na plataforma não pôde ser avaliada por se tratar de área de produção comercial, em que o proprietário solicitou que a colhedora náo parasse durante a operaçáo, para não afetar a capacidade de campo operacional. Porém, determinou-se a média das perdas na plataforma a partir de avaliaçóes realizadas em quatro pontos amostrais, sendo estes valores utilizados para a determinaçáo das demais perdas. Entretanto, constatou-se que, pela colhedora estar configurada com uma plataforma com controle de altura e flutuação lateral conjugados, acionados por sensores elétricos, não houve perdas significativas que poderiam afetar as avaliaçóes in loco das varáveis PGS, PGL e PGT.

Os valores da porcentagem de cobertura vegetal foram obtidos por meio de cordóes de náilon de 9,14 $\mathrm{m}$ com 90 pontos espaçados a cada $0,10 \mathrm{~m}$, para determinar a distribuição de palha realizada pela colhedora, nos 40 pontos amostrais com método adaptado de LAFLEN et al. (1981).

Utilizando-se estatística descritiva permitiu-se a visualização geral do comportamento dos dados (VieIra et al., 2002). Foram calculados a média aritmética, a mediana, máximo, mínimo, desvio-padrão e os coeficientes de variação, assimetria e curtose. A averiguação da normalidade dos dados foi realizada pelo teste de Anderson-Darling. Os métodos estatísticos utilizados para as determinaçóes de perdas foram as cartas de controle para cada variável. As cartas de controle têm como linha central a média geral e amplitude média, bem como os limites superior e inferior de controle, definidos como LSC e LIC, calculados com base no desvio-padrão das variáveis (para LSC, média mais três vezes o desvio-padrão, e para LIC, média menos três vezes o desvio, quando maior que zero).
Os fatores de perdas e distribuição da cobertura vegetal foram comparados com limites aceitáveis, denominados de LIE (limite inferior especificado) e LSE (limite superior especificado). O limite especificado para a perda total em colheita mecanizada de grãos foram de $0 \mathrm{e}$ $60 \mathrm{~kg} \mathrm{ha}^{-1}$, propostos por Costa e TaVares (1995), e para a distribuição da cobertura vegetal, $80 \%$ e $100 \%$ de área coberta, conforme considerado ideal por Toledo et al. (2008), respectivamente, para LIE e LSE.

\section{RESULTADOS E DISCUSSÃO}

A análise descritiva para as características agronômicas da soja (Tabela 1) mostra que somente no número de vagens (NV) houve distribuição de frequência assimétrica, com valores de curtose e assimetria positivo, com a maioria dos valores abaixo da média, além do alto valor de amplitude, ou seja, diferença entre máximo e mínimo. Nas demais variáveis a distribuição de frequência foi normal, com valores de coeficiente de variação considerados médios, segundo (Pimentel-Gomes e Garcia, 2002). Na altura de inserção de primeira vagem os valores médios foram de $0.14 \mathrm{~m}$, concordando com os resultados observados por Júnior et al. (2010), quando afirmam que os padróes normais para altura de corte na colheita mecanizada de soja seria de $0.15 \mathrm{~m}$. O valor observado justifica a não avaliaçáo de perdas ocasionadas por deficiência da altura de corte, devido à inserção da primeira vagem estar próxima ao ideal, reduzindo desse modo as perdas motivadas por vagens náo colhidas

Os resultados da análise descritiva indicam que, no momento da colheita, o teor de água dos grãos (Tabela 2) proporcionou coeficiente de variação médio, considerado normal de acordo com o teste de Anderson-Darling. O valor médio do teor de água dos gráos foi de 13,6\%, considerado próximo ao ideal, pois, de acordo com Embrapa (2005), o teor de água ótimo para colheita da soja está na faixa de $12 \%$ a $14 \%$. Além disso, a regulagem dos mecanismos internos da colhedora (rotação do cilindro de trilha, abertura entre cilindro e côncavo, etc.) pode ser mantida, dentro de certos limites, reduzindo-se, assim, perdas e danos mecânicos, pois não há grande variação no teor de água dos grãos. Neste aspecto, de acordo com

Tabela 1. Análise estatística descritiva para altura de plantas (AP), altura de inserção de primeira vagem (AIV); número de vagens (NV) e produtividade de grãos $(\mathrm{P})$

\begin{tabular}{|c|c|c|c|c|c|c|c|c|c|}
\hline \multirow{3}{*}{ Variável } & \multicolumn{9}{|c|}{ Medidas estatísticas descritivas } \\
\hline & \multirow{2}{*}{ Média } & \multirow{2}{*}{ Mediana } & \multicolumn{2}{|c|}{ Valor } & \multirow{2}{*}{ Desvio-padrão } & \multicolumn{3}{|c|}{ Coeficiente } & \multirow{2}{*}{ Teste* } \\
\hline & & & Mínimo & Máximo & & CV (\%) & Ck & Cs & \\
\hline $\mathrm{AP}(\mathrm{m})$ & 0,70 & 0,70 & 0,42 & 0,89 & 0,10 & 14,67 & 0,30 & $-0,11$ & $\mathrm{~N}$ \\
\hline $\operatorname{AIV}(\mathrm{m})$ & 0,14 & 0,14 & 0,11 & 0,18 & 0,02 & 15,06 & $-1,01$ & 0,35 & $\mathrm{~N}$ \\
\hline NV & 86,34 & 81,50 & 44,60 & 172,20 & 3,70 & 27,13 & 3,31 & 1,33 & A \\
\hline $\mathrm{P}\left(\mathrm{kg} \mathrm{ha}^{-1}\right)$ & 3470 & 3488 & 2588 & 4227 & 425,4 & 12,26 & $-0,20$ & $-0,94$ & $\mathrm{~N}$ \\
\hline
\end{tabular}

Ck: coeficiente de curtose; Cs: coeficiente de assimetria; 'N: distribuição de frequência normal pelo teste de Anderson-Darling (p<0,05); A: distribuição assimétrica. 
Wright et al. (2004), o teor de água ideal para colheita de soja, na faixa de $12 \%$ a $14 \%$, é fundamental para minimizar danos físicos e perdas por quebra de grãos, que são potencializados quando a colheita é realizada com teor de água abaixo de $12 \%$.

A cobertura vegetal (Cob\%) foi distribuída normalmente, devido à semelhança nos valores da média e mediana, bem como, do baixo desvio-padrão, do coeficiente médio de variação, conforme Pimentel-Gomes e Garcia (2002), uma vez que a variabilidade de um atributo pode ser classificada conforme a magnitude do seu coeficiente de variação (FrEDdi et al., 2006). Portanto, para as variáveis de perdas, verifica-se alta variabilidade dos valores encontrados. Para as perdas no sistema de trilha (PGS), sistema de limpeza (PGL) e total (PGT), os valores de assimetria e curtose são positivos, explicando a maior concentração dos valores abaixo da média. Em especial para PGL e PGT, nota-se maior afastamento entre a média e a mediana, explicado pelos altos valores de mínimo e máximo. Para a perda de grãos total (PGT), a distribuição de frequências foi assimétrica, bem como para as perdas PGS e PGL. O coeficiente de curtose positivo para PGS, PGL e PGT demonstra que as perdas tendem a se concentrar em torno da média.

Para as médias de perdas de grãos no sistema de trilha (Figura 1), a distribuição propiciou comportamento instável, considerado fora de controle, pois a amplitude observada entre os pontos 4-5 e 5-6 ultrapassou o limite superior de controle, indicando que causas especiais de variação interferiram no processo, refletindo diretamente sobre o ponto 5, que atingiu perda superior ao LSC, devido à alta variação em relação ao ponto anterior. Estas causas especiais podem ser atribuídas ao aumento da taxa de alimentação da colhedora, uma vez que nos pontos $5 \mathrm{e}$ 6 houve maior quantidade de grãos colhidos (Figura 2) e no ponto 6 houve queda na rotação do motor (Figura 3).

As médias de perdas de grãos no sistema de limpeza e totais ficaram também fora de controle, pois para o

Tabela 2. Análise estatística descritiva para teor de água dos grãos (U\%), cobertura vegetal (Cob), perdas de grãos no sistema de trilha (PGS), sistema de limpeza (PGL) e total (PGT)

\begin{tabular}{|c|c|c|c|c|c|c|c|c|c|}
\hline \multirow{3}{*}{ Variável } & \multicolumn{9}{|c|}{ Medidas estatísticas descritivas } \\
\hline & \multirow{2}{*}{ Média } & \multirow{2}{*}{ Mediana } & \multicolumn{2}{|c|}{ Valor } & \multirow{2}{*}{ Desvio-padrão } & \multicolumn{3}{|c|}{ Coeficiente } & \multirow{2}{*}{ Teste* } \\
\hline & & & Mínimo & Máximo & & CV (\%) & Ck & Cs & \\
\hline U (\%) & 13,55 & 13,65 & 9,00 & 19,70 & 0,42 & 19,55 & $-0,49$ & 0,32 & $\mathrm{~N}$ \\
\hline $\operatorname{Cob}(\%)$ & 71,22 & 71,27 & 42,22 & 88,89 & 1,51 & 13,43 & 0,81 & $-0,51$ & $\mathrm{~N}$ \\
\hline PGS $\left(\mathrm{kg} \mathrm{ha}^{-1}\right)$ & 26,74 & 23,89 & $-1,06$ & 140,83 & 28,04 & 104,88 & 6,03 & 2,07 & A \\
\hline PGL $\left(\mathrm{kg} \mathrm{ha}^{-1}\right)$ & 34,52 & 25,81 & 13,06 & 98,06 & 22,03 & 63,82 & 2,57 & 1,83 & $A$ \\
\hline PGT $\left(\mathrm{kg} \mathrm{ha}^{-1}\right)$ & 61,26 & 50,33 & 17,56 & 201,22 & 6,88 & 70,28 & 1,49 & 1,34 & A \\
\hline
\end{tabular}

Ck: coeficiente de curtose; Cs: coeficiente de assimetria; ' $N$ : distribuição de frequência normal pelo teste de Anderson-Darling ( $\mathrm{p}<0,05)$; A: distribuiçăo assimétrica.
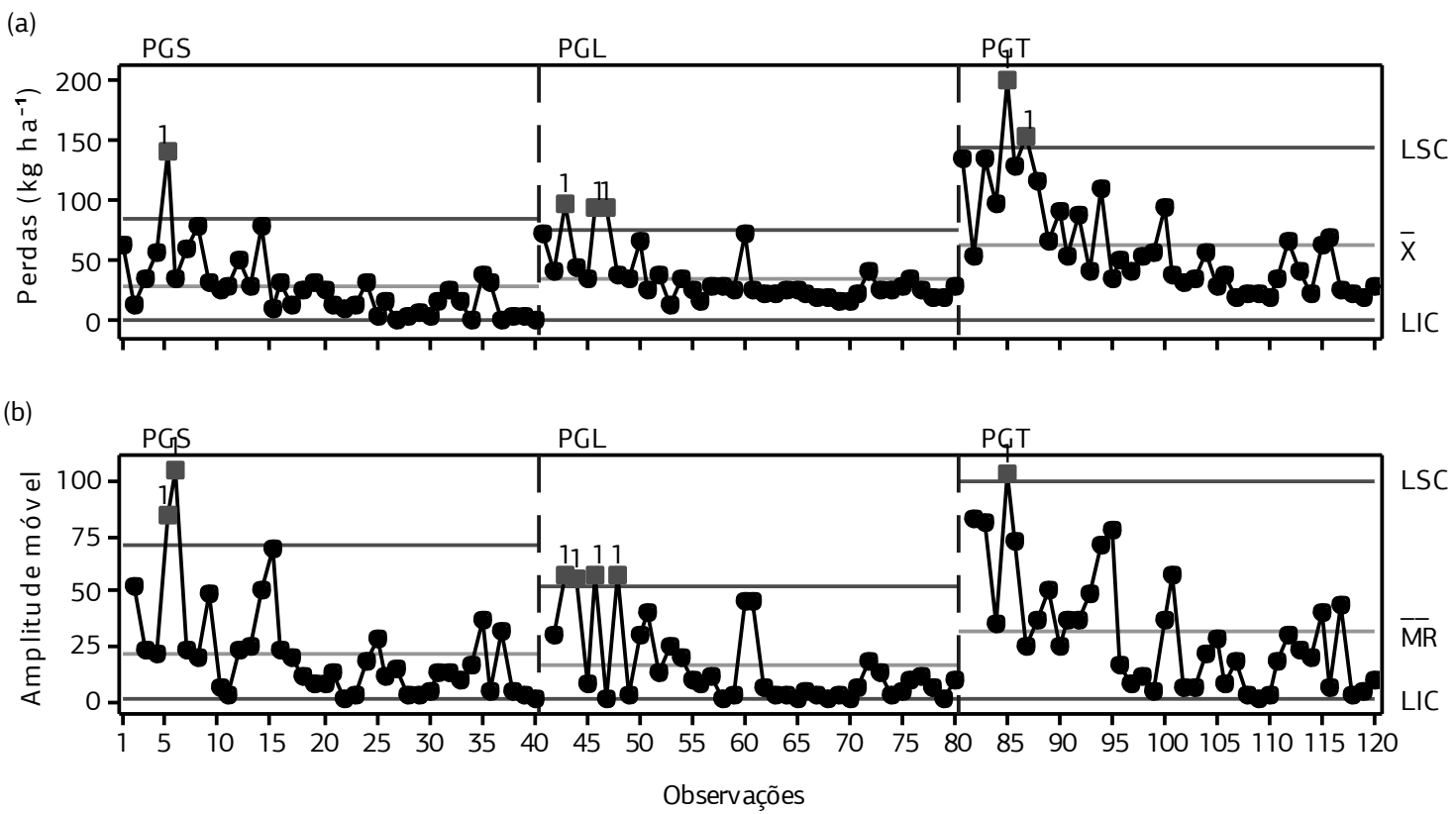

Figura 1. Carta de controle para perdas de grãos $\left(\mathrm{kg} \mathrm{ha}^{-1}\right)$ no sistema de trilha (PGS), sistema de limpeza (PGL) e total (PGT). (a) Carta de valores individuais. (b) Carta de amplitude móvel. LSC: limite superior de controle. LIC: Limite inferior de controle. $\overline{\mathrm{X}}$ e $\overline{\mathrm{MR}}$ : média. 
PGL, nos pontos 2, 3, 5 e 6, a amplitude ultrapassou o limite superior de controle, refletindo sobre os pontos 3, 6 e 7. A amplitude para PGT ultrapassou o LSC no ponto 4, contribuindo diretamente para os valores de PGT nos pontos individuais 5 e 7 . Essas variaçôes dos valores de PGT ocorreram devido ao agrupamento de dados e a oscilação dos dados em relação à média que foi de $61,9 \mathrm{~kg} \mathrm{ha}^{-1}$, proporcionada por alguma causa não inerente ao processo, porém MEsquita et al. (2001), preconiza perdas aceitáveis de $60 \mathrm{~kg} \mathrm{ha}^{-1}$, semelhantes às desta pesquisa. Os valores de PGT são semelhantes aos de CAmpos et al. (2005) que, avaliando perdas na colheita mecanizada de soja, no Estado de Minas Gerais, notaram valores variando de 24 a $126 \mathrm{~kg} \mathrm{ha}^{-1}$.

De acordo com Martins e Laugeni (2005), as causas de variação do processo produtivo são classificadas em dois grupos: causas de variação comuns (ou não assinaláveis) e especiais (ou assinaláveis). Os mesmos autores
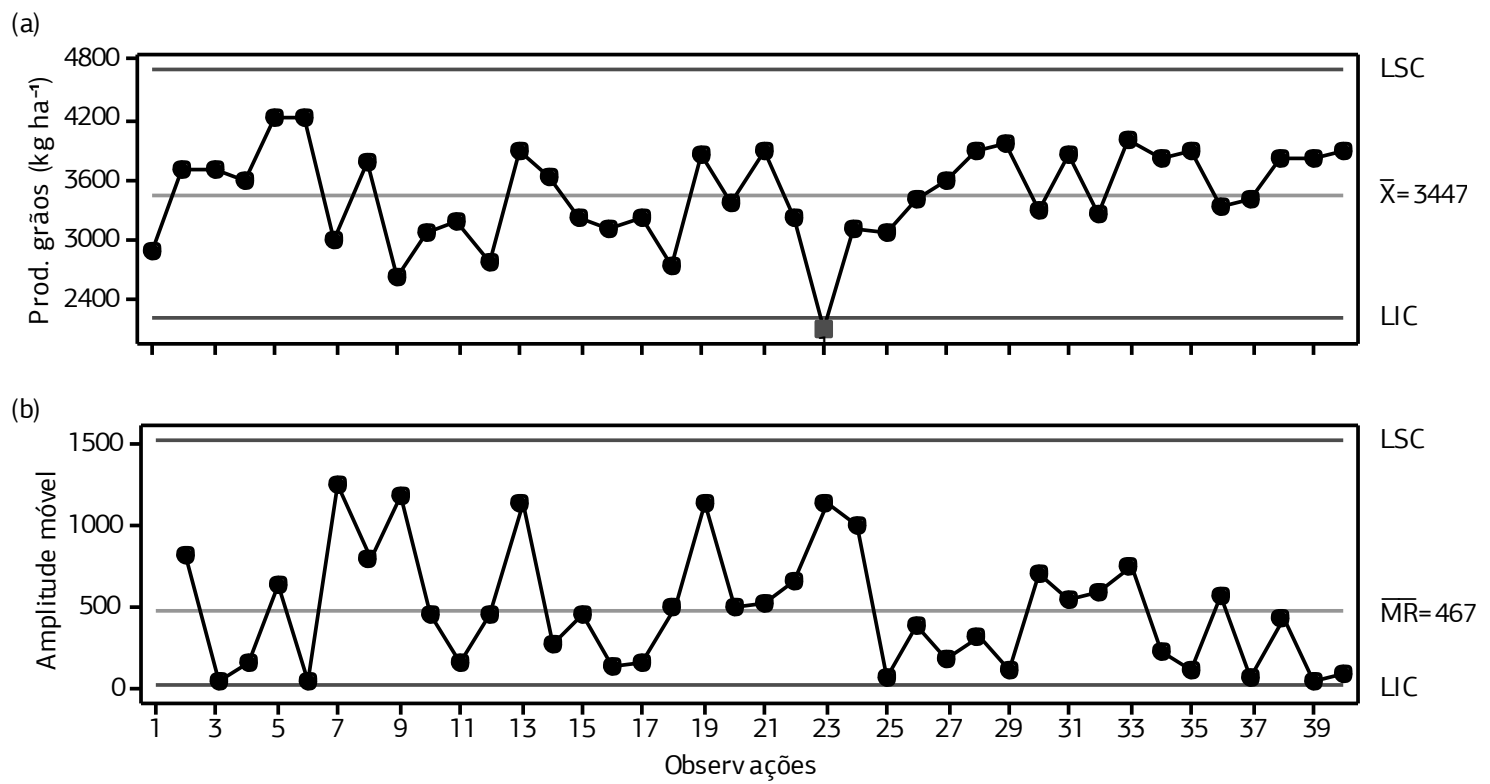

Figura 2. Carta de controle para produtividade de grãos $\left(\mathrm{kg} \mathrm{ha}^{-1}\right)$. (a) Carta de valores individuais. (b) Carta de amplitude móvel. LSC: limite superior de controle. LIC: Limite inferior de controle. $\overline{\mathrm{X}}$ e $\overline{\mathrm{MR}}$ - média.
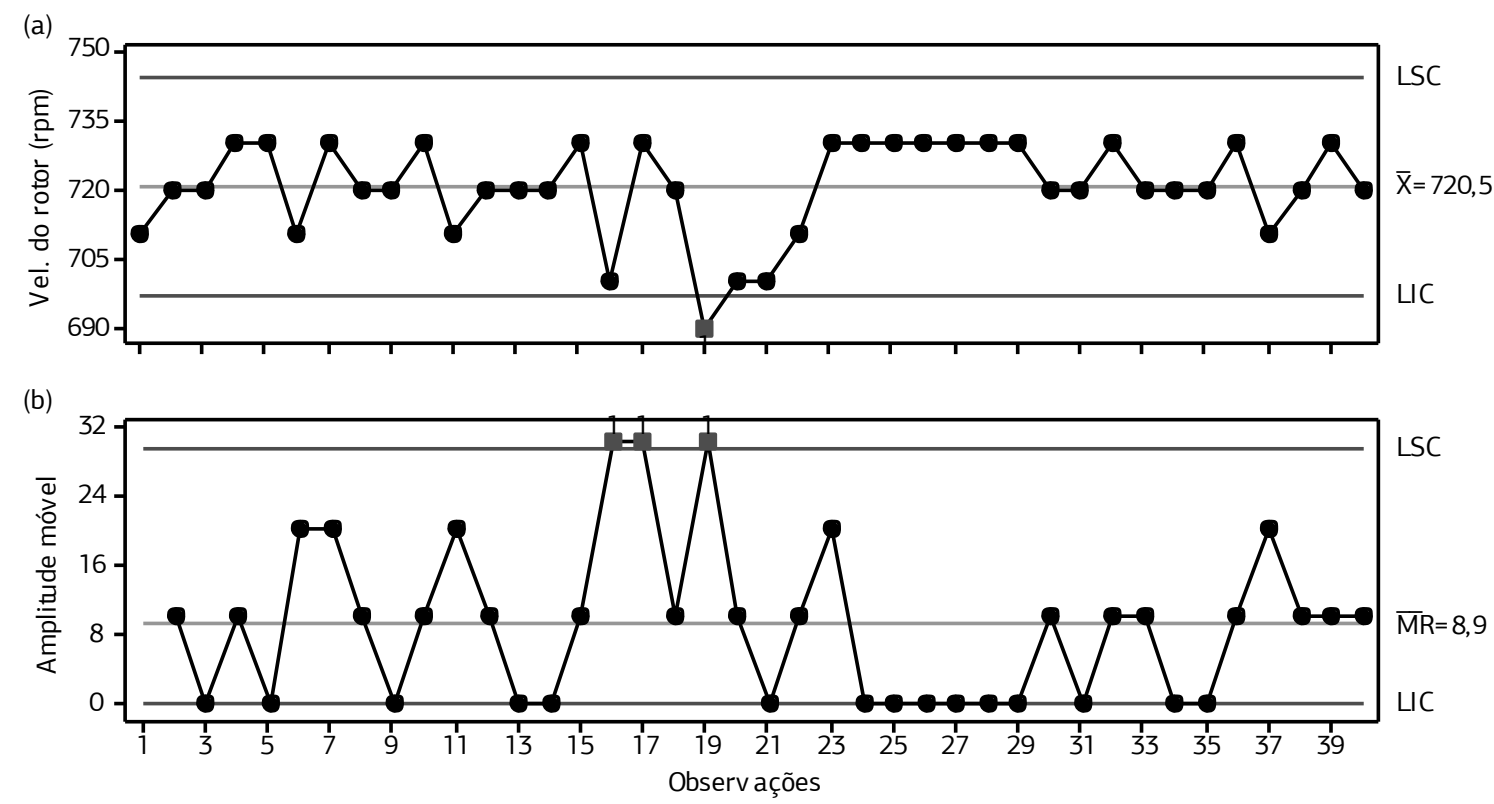

Figura 3. Carta de controle para velocidade do rotor (rpm). (a) Carta de valores individuais. (b) Carta de amplitude móvel. LSC: limite superior de controle. LIC: Limite inferior de controle. $\overline{\mathrm{X}}$ e $\overline{\mathrm{MR}}$ : média. 
afirmam que as causas comuns não podem ser evitadas, e quando o processo contém somente causas de variação comuns, as variáveis do processo seguem uma distribuição normal. Já as causas especiais podem ser eliminadas e são ocasionadas por motivos claramente identificáveis e alteram os parâmetros do processo, média e desvio-padrão. Assim, as causas especiais em operações agrícolas podem estar ligadas a diversos fatores; neste caso, pode-se citar: regulagem incorreta da colhedora, experiência do operador, diferenças nas condiçóes do solo, variaçóes na velocidade de deslocamento, ataque de pragas, entre outros.

Para a média de produtividade (Figura 2), verifica-se comportamento estável na distribuição dos valores, com os mesmos dentro dos limites aceitáveis de controle inferior e superior. A distribuição dos valores torna-se próxima da média a partir do ponto 25 , podendo estar relacionada com a uniformidade dos atributos físicos e químicos do solo, refletindo na produtividade estável no decorrer dos pontos. Para essa variável, a média de produtividade de grãos avaliada foi de $3470 \mathrm{~kg} \mathrm{ha}^{-1}\left(57,8\right.$ sacas ha $\left.{ }^{-1}\right)$, estando $11,4 \%$ da média brasileira (ConAB, 2011).

A potência no motor (PM) e o consumo de combustível (C) tiveram distribuição de frequência normal (Tabela 3), e a concentraçấo dos valores ao redor da média, por sua vez próximo da mediana, foram diferentes das demais, com distribuição assimétrica. Para todas as variáveis verifica-se que os valores de assimetria são negativos e os valores de curtose são positivos, explicando o porquê da maioria dos pontos terem valores acima da média.

Para as médias das especificaçóes da colhedora e regulagens, ou seja, para os valores das variáveis analisadas, todas tiveram istribuição instável, fora do limite superior e/ou inferior de controle. A explicação para essas variaçôes é devido às causas inerentes ao processo, principalmente a variação da velocidade de deslocamento da colhedora. A variação na velocidade promove maior ou menor fluxo de material presente dentro dos mecanismos internos, que afetam de maneira significativa os padróes aceitáveis de

Tabela 3. Análise estatística descritiva para potência no motor (PM, cv), rotação no motor (RPM), velocidade do rotor (VR, rpm), velocidade de deslocamento $\left(\mathrm{V}, \mathrm{km} \mathrm{h}^{-1}\right)$ e consumo de combustível $\left(\mathrm{C}, \mathrm{L} \mathrm{h}^{-1}\right)$

\begin{tabular}{|c|c|c|c|c|c|c|c|c|c|}
\hline \multirow{3}{*}{ Variável } & \multicolumn{9}{|c|}{ Medidas estatísticas descritivas } \\
\hline & \multirow{2}{*}{ Média } & \multirow{2}{*}{ Mediana } & \multicolumn{2}{|c|}{ Valor } & \multirow{2}{*}{ Desvio-padrão } & \multicolumn{3}{|c|}{ Coeficiente } & \multirow{2}{*}{ Teste $^{*}$} \\
\hline & & & Mínimo & Máximo & & CV (\%) & Ck & Cs & \\
\hline PM & 295 & 299 & 197 & 347 & 29,26 & 9,91 & 2,15 & $-0,95$ & $\mathrm{~N}$ \\
\hline RPM & 2097 & 2100 & 2050 & 2130 & 16,9 & 0,81 & 2,96 & $-1,44$ & A \\
\hline VR & 721 & 720 & 690 & 730 & 10,37 & 1,44 & 0,86 & $-1,12$ & A \\
\hline V & 7,06 & 7,3 & 4,5 & 8,3 & 1,00 & 14,21 & 0,38 & $-1,18$ & $A$ \\
\hline C & 48,7 & 48,9 & 31,1 & 62,1 & 5,75 & 11,80 & 1,39 & $-1,51$ & $\mathrm{~N}$ \\
\hline
\end{tabular}

Ck: coeficiente de curtose; Cs: coeficiente de assimetria; ${ }^{\circledR} \mathrm{N}$ : distribuiçấo de frequência normal pelo teste de Anderson-Darling (p<0,05); A: distribuiçăo assimétrica.

(a)
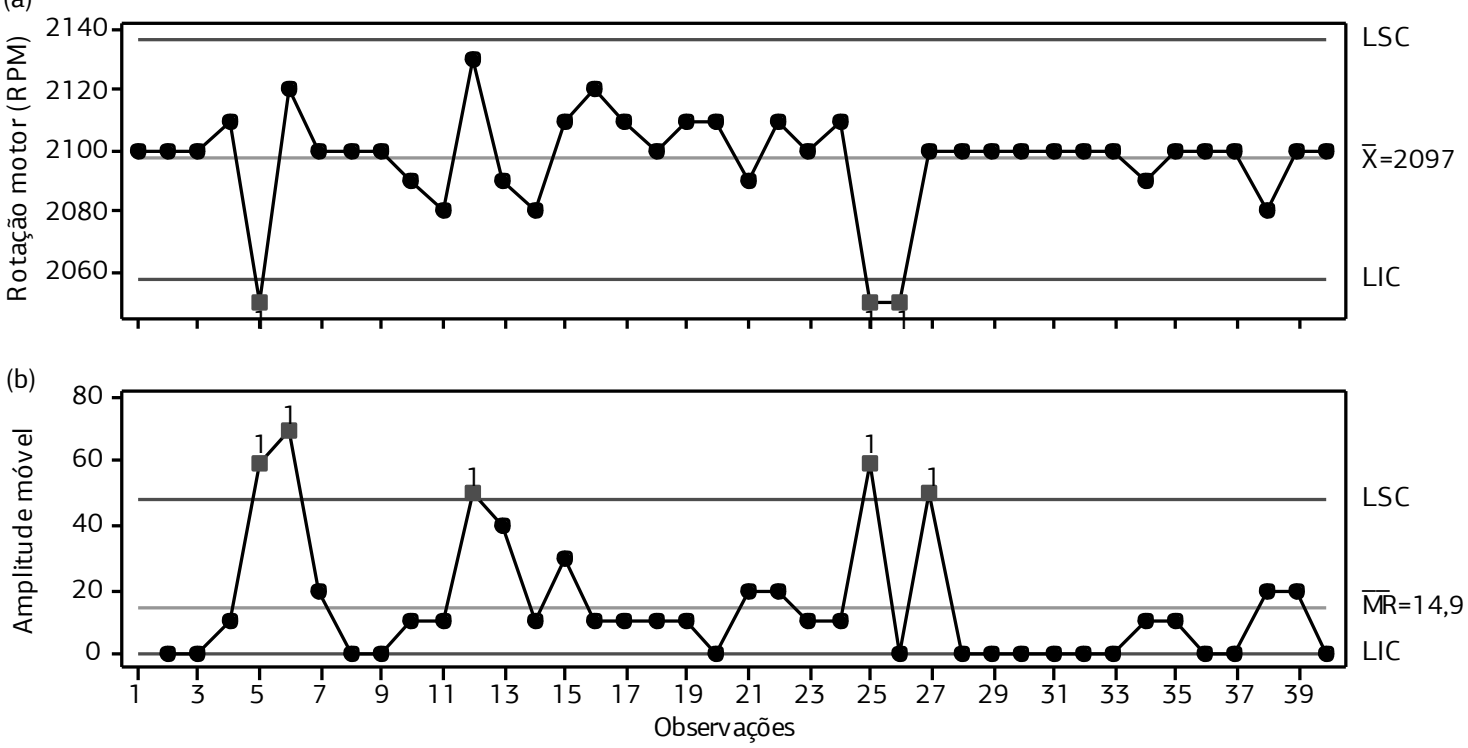

Figura 4. Carta de controle para rotação do motor (rpm). (a) Carta de valores individuais. (b) Carta de amplitude móvel. LSC: limite superior de controle. LIC: Limite inferior de controle. $\overline{\mathrm{X}}$ e $\overline{\mathrm{MR}}$ : média. 
controle. A potência e rotação no motor, velocidade do rotor e consumo de combustível tiveram número de execuçóes em relação à mediana, acima ou abaixo, menor que o esperado, indicando agrupamento e presença de tendência dos dados analisados. Para a velocidade de deslocamento, houve agrupamento e oscilação dos dados, porém com valores próximos da média a partir do ponto 21 (Figura 6). As variáveis dependentes da colhedora (Figuras 3, 4, 5 e 7) são afetadas diretamente de acordo com a variação da velocidade de deslocamento. Verifica-se que, com velocidade próxima da média e constante, nas demais características a distribuição foi estável, assim como as perdas, confirmando a importância da velocidade no sistema, pois tais perdas foram menores nas velocidades próximas da média (Figura 1). Esses resultados são semelhantes aos analisados por Ferreira et al. (2007) que, em função da variação da velocidade de deslocamento, obtiveram maiores perdas nas menores velocidade de colheita.
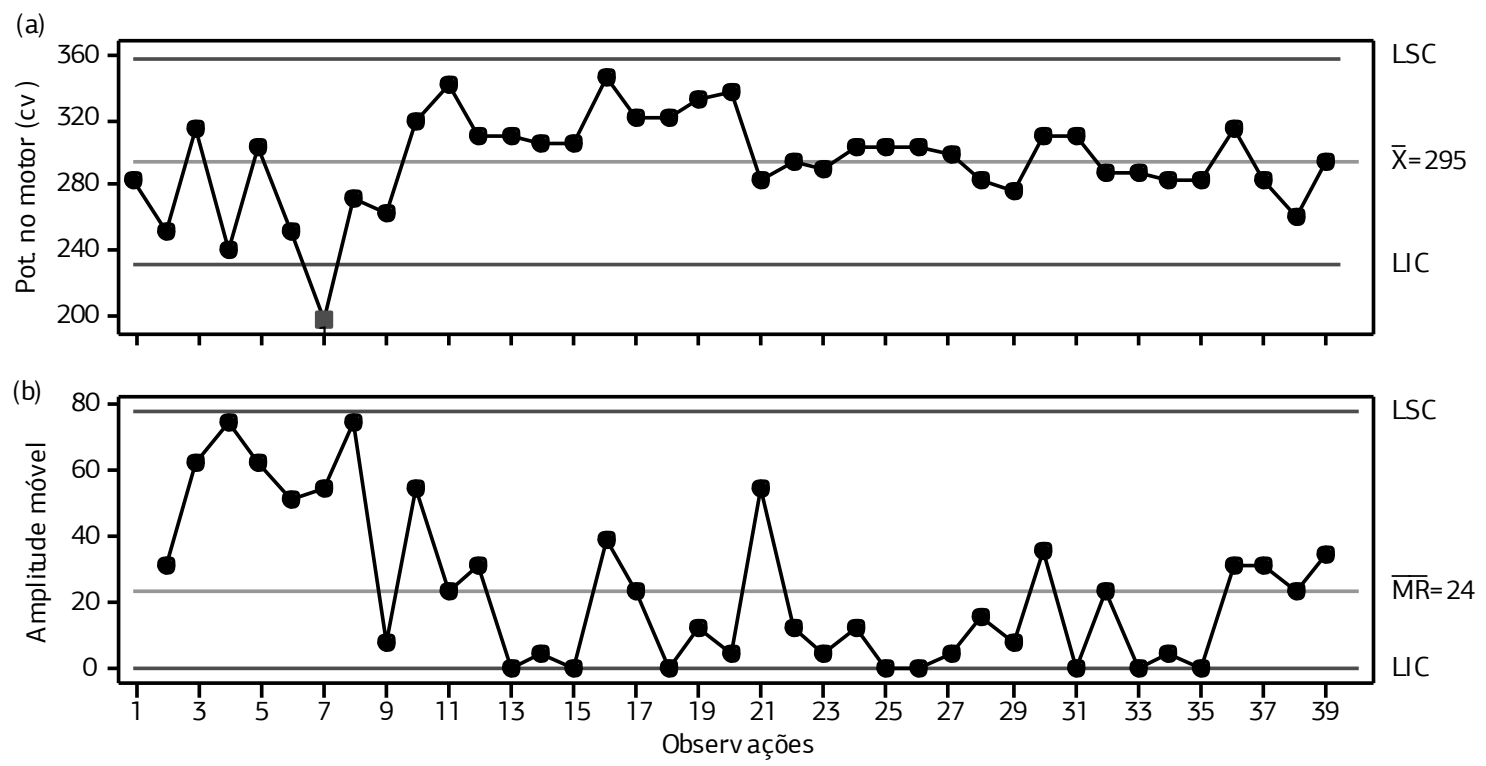

Figura 5. Carta de controle para potência no motor (cv). (a) Carta de valores individuais. (b) Carta de amplitude móvel. LSC: limite superior de controle. LIC: Limite inferior de controle. $\overline{\mathrm{X}}$ e $\overline{\mathrm{MR}}$ : média.

(a)

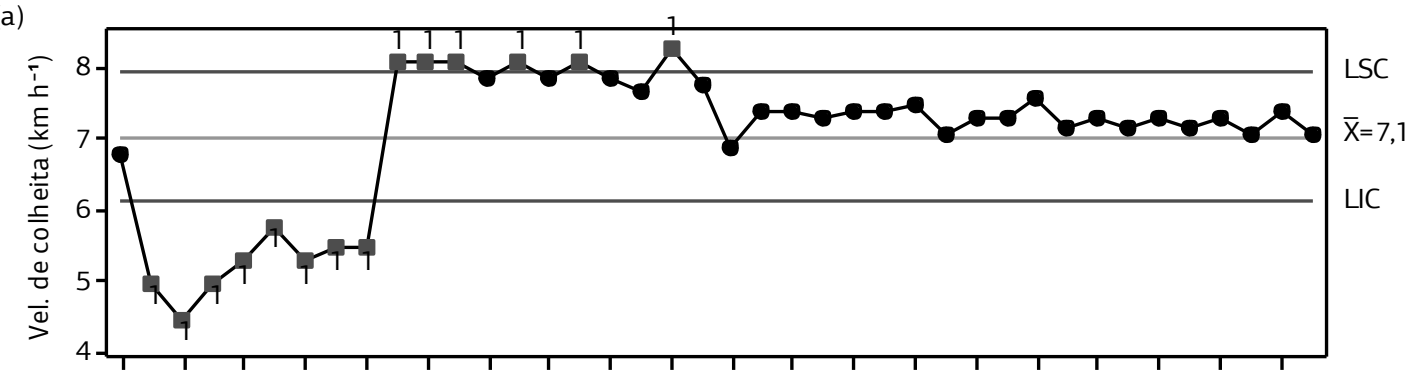

(b)

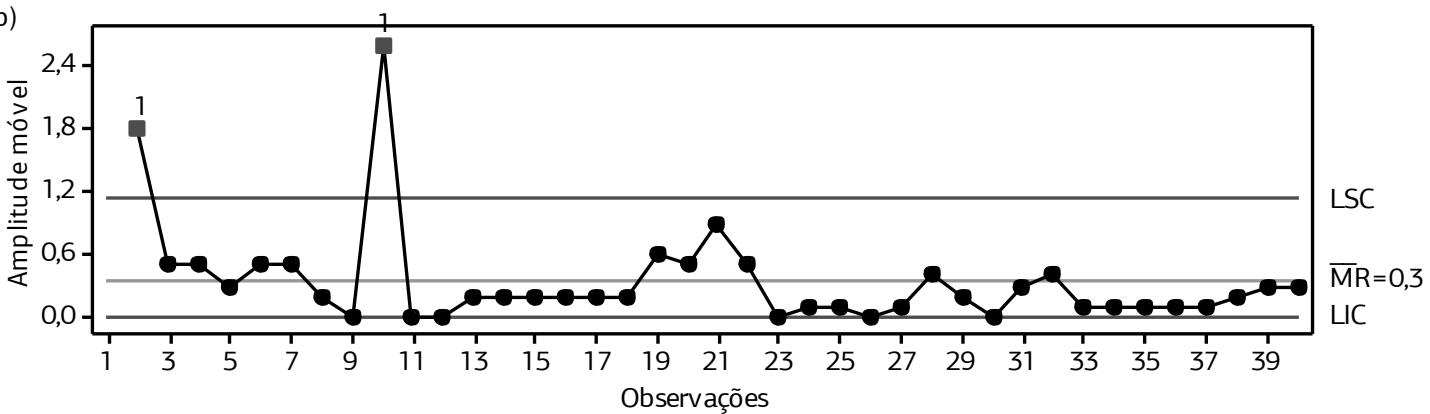

Figura 6. Carta de controle para velocidade de colheita $\left(\mathrm{km} \mathrm{h}^{-1}\right)$. (a) Carta de valores individuais. (b) Carta de amplitude móvel. LSC: limite superior de controle. LIC: Limite inferior de controle. $\overline{\mathrm{X}}$ e $\overline{\mathrm{MR}}$ : média. 
Para o consumo de combustível (Figura 7), verifica-se comportamento instável das observaçôes. A amplitude está fora de controle, bem como os valores individuais 7 e 16 também estâo fora de controle, ultrapassando o LIC e o LSC respectivamente. Comparando-se a figura 6 com a 7 , na figura 6 nota-se claramente que o consumo é dependente da variável principal velocidade, ou seja, a partir do ponto 21 , a velocidade é constante e próxima da média, refletindo diretamente no consumo de combustível, que também se torna próximo da média e dentro dos limites de controle. O consumo médio horário foi de $48,67 \mathrm{~L} \mathrm{~h}^{-1}$ correspondendo a $7,54 \mathrm{~L} \mathrm{ha}^{-1}$, semelhante ao analisado por MAzeTto e LANÇAS (2009). Os autores avaliaram três colhedoras com larguras de plataforma diferentes e equipadas com medidor de combustível do tipo "fluxômetro" de marca Flowmate Oval MIII, modelo FLSN 45. Eles concluíram que a

(a)
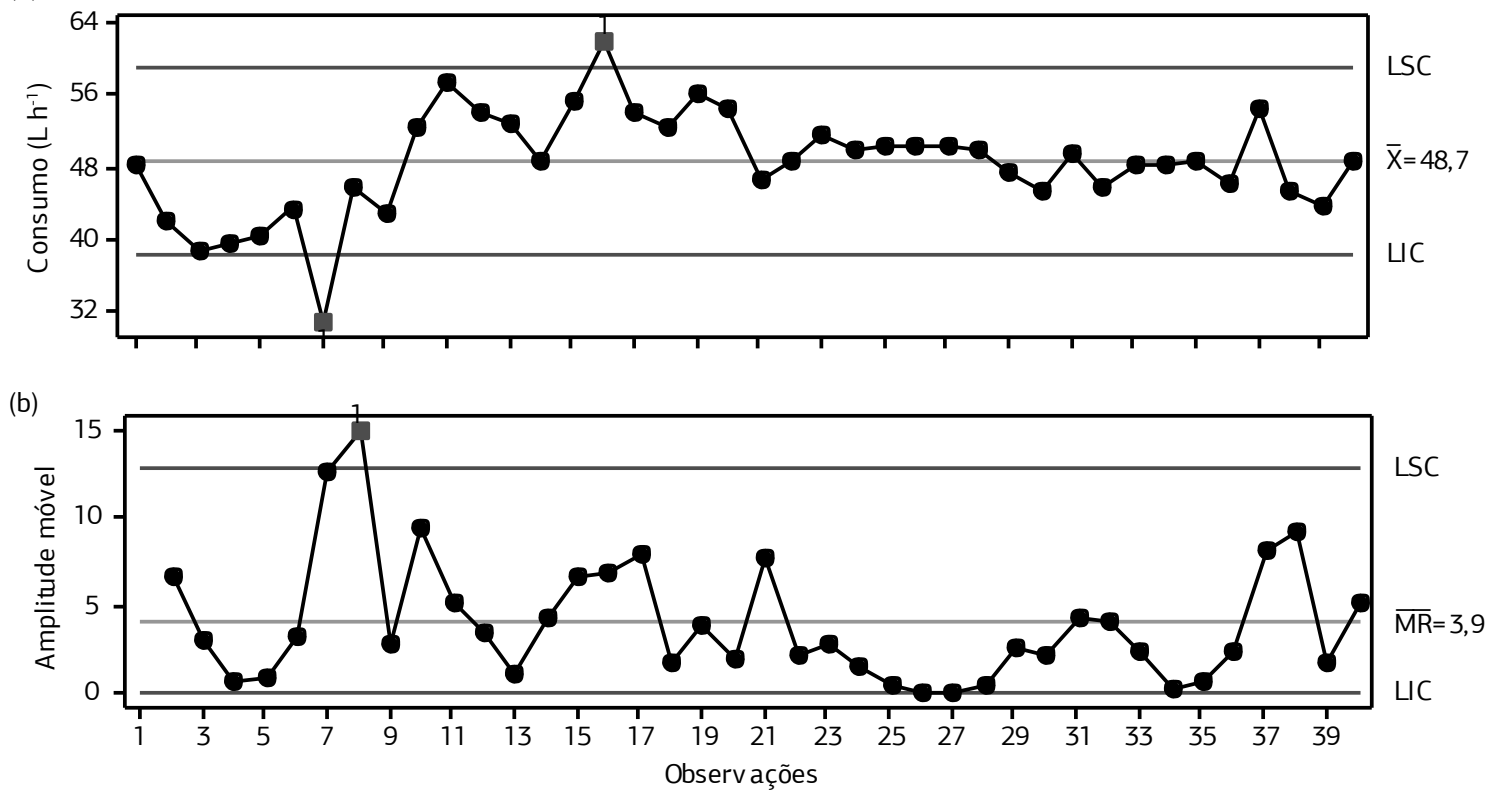

Figura 7. Carta de controle para Consumo $\left(\mathrm{L} \mathrm{h}^{-1}\right)$. (a) Carta de valores individuais. (b) Carta de amplitude móvel. LSC: limite superior de controle. LIC: Limite inferior de controle. $\overline{\mathrm{X}} \mathrm{e} \overline{\mathrm{MR}}$ : média.

(a)

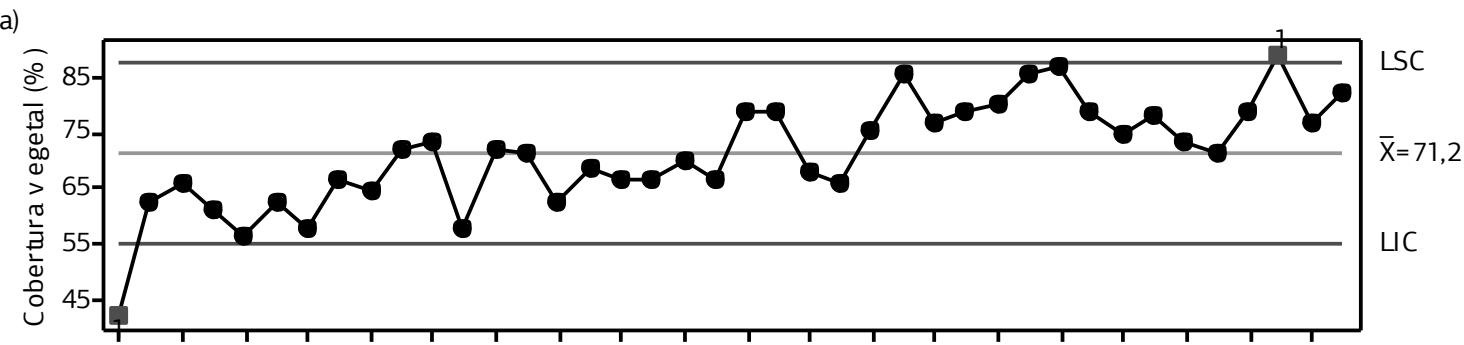

(b)

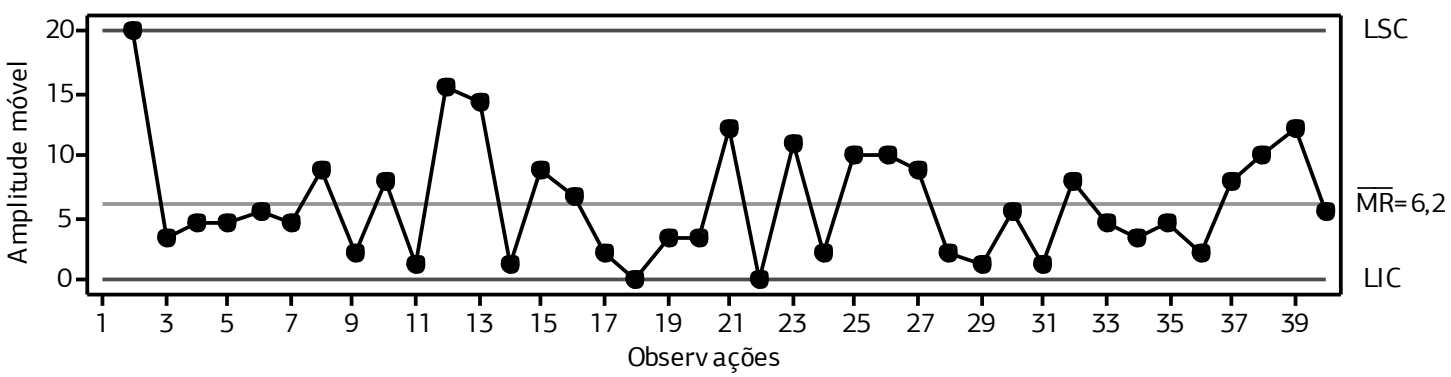

Figura 8. Carta de controle para a distribuiçáo de cobertura vegetal (\%) após a colheita mecanizada da soja. (a) Carta de valores individuais. (b) Carta de amplitude móvel. LSC: limite superior de controle. LIC: Limite inferior de controle; $\overline{\mathrm{X}}$ e $\overline{\mathrm{MR}}$ : média. 
utilização de colhedoras com larguras maiores de plataforma proporcionou menor consumo de combustível por área.

O controle na uniformidade de distribuição da palha pela colhedora pode ser observado pelo coeficiente de variaçáo de $13,43 \%$ (Tabela 1). A porcentagem de distribuição da cobertura vegetal manteve-se fora de controle (Figura 8), ou seja, os pontos 1 e 38 estão fora dos limites inferior e superior de controle; o ponto 38 , porém, é considerado desejável, pois localiza-se entre os limites inferior e superior especificados, que é de $80 \%$ a $100 \%$. Para essa variável, a média encontrada foi de $71,22 \%$ de solo coberto, valor considerado baixo, principalmente para o funcionamento adequado da semeadora em sistema plantio direto (Prado et al., 2002). Resultados semelhantes foram constatados por KunZ et al. (2008) que, avaliando a distribuição de palha de diversas colhedoras na região de Cascavel (PR), observou que as colhedoras equipadas com distribuidor de palha proporcionaram distribuição mais próxima do limite considerado aceitável. Já Toledo et al. (2008) verificaram que a distribuição de cobertura vegetal após a colheita mecanizada manteve-se em processo controlado e com a maioria dos valores entre os limites inferior e superior especificados. Por esses resultados, observa-se a importância de uma regulagem adequada dos mecanismos de distribuição de palha e palhiço da colhedora, principalmente na agricultura de precisão relacionada aos atributos químicos do solo, que visa à uniformidade dos nutrientes na área com a finalidade de obter produtividade uniforme e sustentabilidade do sistema de produção agrícola.

\section{CONCLUSÃO}

A perda de grãos ocasionada pela colhedora nos sistemas de trilha e de limpeza, bem como a perda total estáo fora dos limites de controle, porém dentro dos padróes aceitáveis de perdas para cultura da soja.

As especificações e regulagens da colhedora são dependentes da velocidade de deslocamento.

A distribuição de palha se mantém dentro dos padróes considerados aceitáveis para o sistema de semeadura direta.

\section{AGRADECIMENTOS}

À Fundação de Amparo à Pesquisa do Estado de São Paulo, (FAPESP) pela concessão da bolsa de Doutorado ao primeiro autor.

\section{REFERÊNCIAS}

BONILLA, J.A. Qualidade total na agricultura: fundamentos e aplicaçóes. 2.ed. Belo Horizonte: Centro de Estudos de Qualidade Total na Agricultura, 1994. 344p.
CAMPOS, M.A.O.; SILVA, R.P.; CARVALHO FILHO, A.; MESQUITA, H. C.B.; ZABANI, S. Perdas na colheita mecanizada de soja no estado de Minas Gerais. Engenharia Agrícola, v.25, p.207-213, 2005.

CARVALHO FILHO, A.; CORTEZ, J.W.; SILVA R.P.; ZAGO, M.S. Perdas na colheita mecanizada de soja no triângulo mineiro. Revista Nucleus, v.3, p.57-60, 2005.

CONAB. COMPANHIA BRASILEIRADEABASTECIMENTO. Acompanhamento da safra brasileira: grãos, sexto levantamento, 2011. Brasília, 2011. 40p

COSTA, N.P.; TAVARES, L.C.V. Fatores responsáveis pelos elevados percentuais de perdas de grãos durante a colheita mecânica de soja. Informativo ABRATES, v.5, p.17-25, 1995.

EMPRESA BRASILEIRA DE PESQUISA AGROPECUÁRIA EMBRAPA. Sistema Brasileiro de Classificação de Solos. 2.ed. Rio de Janeiro: Embrapa Solos, 2006. 306p.

EMPRESA BRASILEIRA DE PESQUISA AGROPECUARIA. Tecnologias de produçáo de soja. Londrina: Embrapa Soja, 2005. 224p. (Sistemas de produção/EMBRAPA Soja, n.5)

FERREIRA, I.C.; SILVA, R.P.; LOPES, A.; FURLANI, C.E.A. Perdas quantitativas na colheita de soja em funçáo da velocidade de deslocamento e regulagens no sistema de trilha. Engenharia na Agricultura, v.15, p.141-150, 2007.

FREDDI, O.S.; CARVALHO, M.P.; VERONESI JÚNIOR, V.; CARVALHO, G.J. Produtividade do milho relacionada com a resistência mecânica à penetração do solo sob preparo convencional. Engenharia Agrícola, v.26, p.113-121, 2006.

KUNZ, V.L.; FILHO, A.G.; PRIMO, M.A.; GURGACZ, F.; FEY, E. Distribuição de palha por colhedoras autopropelidas na colheita da soja. Engenharia Agrícola, v.28, p.125-135, 2008.

LAFLEN, J.M.; AMEMIYA, A.; HINTZ, E.A. Measuring crop residue cover. Soil and Water Conservation, v.36, p.341-343, 1981.

MARTINS, P.G.; LAUGENI, F.R. Administração da produção. 2.ed. São Paulo: Editora Saraiva, 2005.

MAZETTO, F.R.; LANÇAS, K.P. Avaliação do desempenho operacional e energética de colhedoras na cultura da soja ( Glicyne $\operatorname{Max}(\mathrm{L})$ Merril). Energia na Agricultura, v.24, p.106-118, 2009.

MESQUITA, C.M.; COSTA, N.P.; MANTOVANI, E.C.; ANDRADE, J.G.M.; FRANÇA NETO, J.B.; SILVA, J.G.; FONSECA, J.R.; PORTUGAL, F.A.F.; GUIMARÃES SOBRINHO, J.B. Manual do produtor: Como evitar desperdícios nas colheitas da soja, do milho e do arroz. Londrina: EMBRAPACNPSo, 1998. p.19-22.

MESQUITA, C.M.; COSTA, N.P.; PEREIRA, J.E.; MAURINA, A.C.; ANDRADE, J.G.M. Caracterização da colheita mecanizada da soja no Paraná. Engenharia Agrícola, v.21, p.197-205, 2001.

MESQUITA, C.M.; HANNA, M.A.; COSTA, N.P. Crop and harvesting operation characteristics affecting field losses and physical qualities of soybeans - Part I. Applied Engineering in Agriculture, v.22, p. 325-333, 2006. 
MINGOTI, S.A.; FIDELIS, M.T. Aplicando a geoestatística no controle estatístico de processo. Revista Produto e Produção, v.5, p.55-70, 2001.

PEREIRA JÚNIOR, P.; REZENDE, P.M.; MALFITANO, S.C.; LIMA, R.K.; CORRÊA, L.V.T.; CARVALHO, E.R. Efeito de doses de silício sobre a produtividade e características agronômicas da soja [Glycine $\max (\mathrm{L}$.$) ]. Ciência e Agrotecnologia, v.34, p.908-$ 913,2010

PIMENTEL-GOMES, F.; GARCIA, C.H. Estatística aplicada a experimentos agronômicos e florestais: exposição com exemplos e orientaçóes pra uso de aplicativos. Piracicaba: FEALQ, 2002. 309p.

PRADO, R.M.; NATALE, W.; FURLANI, C.E.A. Manejo mecanizado de atividades para implantação de culturas. Jaboticabal: Sociedade Brasileira de Engenharia Agrícola, 2002. 99p. (Série Engenharia Agrícola)
TOLEDO, A.; TABILE, R.A.; SILVA, R.P.; FURLANI, C.E.A.; MAGALHÂES, S.C.; COSTA, B. Caracterização das perdas e distribuição de cobertura vegetal em colheita mecanizada de soja. Engenharia Agrícola, v.28, p.710-719, 2008.

VIEIRA, S.R.; MILLETE, J.; TOPP, G.C.; REYNOLDS, W.D. Handbook for geoestatical analysis of variability in soil and climate data. In: ALVAREZ V.V.H.; SCHAEFER, C.E.G.R.; BARROS, N.F.; MELLO, J.W.V.; COSTA, L.M. (Ed.). Tópicos em ciência do solo. Viçosa: Sociedade Brasileira de Ciência do Solo, 2002. v.2, p. $1-45$.

WRIGHT, D.L.; RICH, J.R.; MAROIS, J.J.; SPRENKEL, R.K. Soybean production in Florida. Gainesville, Fla.: University of Florida, Extension, Institute of Food and Agricultural Sciences. Disponível em: <http://edis.ifas.ufl. edu/pdffiles/AG/AG18500.pdf>. 